\title{
How Disorder-Specific are Depressive Attributions? A Comparison of Individuals with Depression, Post-Traumatic Stress Disorder and Healthy Controls
}

\author{
Désirée Gonzalo • Birgit Kleim • Catherine Donaldson • \\ Stirling Moorey • Anke Ehlers
}

Published online: 27 December 2011

(C) The Author(s) 2011. This article is published with open access at Springerlink.com

\begin{abstract}
Depressed individuals tend to assign internal, stable, and global causes to negative events. The present study investigated the specificity of this effect to depression and compared depressive attributional styles of individuals with major depression (MD), post-traumatic stress disorder (PTSD), and healthy controls. We indexed attributional style using the depressive attributions questionnaire in 164 participants. Additionally, we assessed appraisals characteristic of PTSD using the post-traumatic cognitions inventory (PTCI), depressive rumination, trauma history, and depression and PTSD symptom severity. Individuals with MD
\end{abstract}

D. Gonzalo $(\square)$

Department of Psychology, University of New York in Prague,

Legerova 72, 12000 Prague, Czech Republic

e-mail: dgonzalo@faculty.unyp.cz

B. Kleim

Department of Psychology, University of Zürich, Zurich,

Switzerland

C. Donaldson · A. Ehlers

Institute of Psychiatry, King's College London, London, UK

C. Donaldson

Affective Disorders Unit, Maudsley Hospital, London, UK

S. Moorey · A. Ehlers

NIHR Biomedical Research Centre for Mental Health, South London \& Maudsley NHS Trust and King's College London, London, UK

S. Moorey

CBT Psychotherapy Unit, Maudsley Hospital, London, UK

A. Ehlers

Department of Experimental Psychology, Oxford University, Oxford, UK endorsed a depressive attributional style to a greater extent than both individuals with PTSD, who were not depressed, and healthy controls. Depressive attributional style was associated with the severity of depressive and PTSD symptoms, number and distress of traumatic experiences, frequency of rumination, and post-traumatic cognitions. Depressive attributions and PTCI appraisals independently predicted MD and PTSD symptom severity. They may thus be useful in predicting MD and PTSD, and should be targeted in psychological treatments of these conditions.

Keywords Attributional style - Depression - PTSD . Depressive attributions questionnaire $\cdot$ Cognitive factors

\section{Introduction}

People respond differently to stressful or traumatic life events. Negative cognitions about the self, the world, and the future, are thought to play a crucial role in the development of depression (Beck 1967, 1976). There is evidence that depression is characterised by a certain attributional style, also known as depressive attributional style or pessimistic explanatory style (Sweeney et al. 1986; Zullow et al. 1988). According to the reformulated model of learned helplessness and depression (Abramson et al. 1978), depressed individuals tend to attribute negative events to internal ("it is due to me"), stable ("it is permanent") and global ("it will affect other areas of my life") causes, and positive events to external ("it is not due to me"), unstable ("it is temporary"), and specific ("it will only affect this area of my life") causes (see Sweeney et al. 1986, for a review). There is empirical evidence that attributional style is an important factor in the development and maintenance of depression (e.g., Ball et al. 2008; 
Elwood et al. 2009a, b; Southall and Roberts 2002). The hopelessness theory of depression (Abramson et al. 1988; Alloy et al. 1988) further specifies that individuals who make stable and global attributions following a negative event may experience hopelessness and, in turn, develop depression. A relationship between attributional style, hopelessness and later depression has previously been found in various samples, such as undergraduate students, adolescent psychiatric inpatients, or healthy participants at high versus low cognitive risk for depression (e.g., Abramson et al. 1998; Alloy et al. 2006; Gibb et al. 2001; Hilsman and Garber 1995; Voelz et al. 2003). Thus, the meaning and interpretation given to negative experiences may influence whether an individual becomes depressed, whether they are vulnerable to recurrent episodes of depression and how long and severe these episodes will be (Alloy et al. 1999).

Individual differences in the interpretation and personal meanings of traumatic events, which can be understood as extremely negative events, have been the focus of theoretical models of posttraumatic stress disorder (PTSD) (e.g., Dollinger 1986; Ehlers and Clark 2000; Foa and Riggs 1993; Resick and Schnicke 1993; Taylor 1983). Trauma-related appraisals about the self (e.g., "I am weak"), the world (e.g. "I cannot trust anybody"), and selfblame (e.g., "It was my fault that the event happened") have been shown to predict PTSD after a range of traumatic events (e.g., Ehring et al. 2008; Foa et al. 1999; Halligan et al. 2003; Laposa and Alden 2003). In line with the findings on increased self-blame in PTSD, several studies have found that internal, global and stable attributions of traumatic events are associated with PTSD symptoms in war veterans and survivors of childhood sexual abuse or disaster (Frye and Stockton 1982; Ginzburg et al. 2003; Gray et al. 2003; Joseph et al. 1991; McCormick et al. 1989; Wenninger and Ehlers 1998). One interpretative problem in these studies is that PTSD is often comorbid with depression (e.g., Breslau et al. 1991; Kessler et al. 1995; Shalev et al. 1998) so that it remains unclear whether the associations between attributional style and trauma reactions are due to PTSD or due to depression. The present study was designed to address this question.

Overall, there is very limited research on the specificity of cognitive factors in response to negative events (for exceptions see Ehring et al. 2008; Kleim et al. in press; Mayou et al. 2001; O'Donnell et al. 2004). Some research has provided initial evidence for a specificity of certain cognitive styles, including depressive attributional styles, to depression. For instance, Hankin et al. (2004) found that the interaction between cognitive vulnerability for depression, including depressive attributions, and negative events, specifically predicted future depression. Studies by Ehring et al. (2008) and Kleim et al. (in press) demonstrated a relative specificity of theory-derived cognitive factors in the prediction of depression and PTSD.

Based on the above reviewed studies, it seems relevant to clarify the nature and extent of overlap and specificity of attributions in MD and PTSD, and index depressive attributions, as well as trauma-specific appraisals characteristic of PTSD in such samples. If a depressive attributional style and trauma-specific appraisals were disorder-specific, this could point to separate mechanisms of development and maintenance of the two disorders and a need to target these cognitions in treatment.

The aim of this study was to compare depressive attributions in individuals with depression only, PTSD only, and PTSD comorbid with depression. We aimed to investigate the specificity of depressive attributions, i.e., whether depressed individuals endorse depressive attributions to a greater extent than those with PTSD. Moreover, we wanted to test the relationship between depressive attributions and the severity of depression and PTSD symptoms, the number and distress of traumatic experiences, trauma-related appraisals, and the frequency of rumination. The latter is thought to maintain both depression (Nolen-Hoeksema 1991; Nolen-Hoeksema et al. 2008) and PTSD (Ehlers and Clark 2000). According to the studies presented above, we hypothesised some overlap between depression and PTSD in terms of attributional style and expected that depressive attributions may predict the severity of both depression and PTSD. However, we also predicted that attributional style would be more closely related to major depression than to PTSD.

\section{Methods}

Participants

Four groups of adult participants (ages 18-65 years) were recruited for the study. Participants had to meet the criteria specified below and had to be sufficiently fluent in English to complete the questionnaires. Exclusion criteria were psychosis, clinically significant head injury, ongoing domestic violence, and no memory for the traumatic events that participants had experienced.

Patients with Major Depression $(\mathrm{N}=20)$ were recruited from inpatient and outpatient clinics at the Maudsley Hospital, London, UK.

Trauma Survivors with PTSD. Participants with PTSD were recruited from trauma survivors who had attended King's College Hospital's A\&E Department following an assault, from outpatient clinics at the Maudsley Hospital, and through flyers at local newsagents. Of the 43 trauma survivors with PTSD, 17 had PTSD without comorbid depression and 26 had PTSD with comorbid major depression. 
Control Participants $(\mathrm{N}=101)$ who did not suffer from depression or PTSD were recruited from trauma survivors who had attended King's College Hospital's A\&E Department following an assault, through flyer and poster advertisement at local shops, through a database of volunteers, and through emails to staff.

Table 1 shows the differences between the groups in terms of level of symptoms and scores obtained from the measures described below, as well as demographic information. Oneway ANOVAs revealed significant differences between the groups in depression $(F(3,159)=70.33, P<0.001)$ and PTSD symptom severity $(F(3,158)=55.96, P<0.001)$, number of traumatic events $(F(3,160)=4.06, P<0.01)$, and total distress scores resulting from past traumatic events $(F(3,157)=4.96, P<0.01)$. Posthoc comparisons showed that the MD + PTSD group scored higher than healthy controls on all measures. Additionally, the MD only and the PTSD only groups also differed from healthy controls in depression and PTSD symptom severity, but not in the number of traumatic events or distress scores.

\section{Diagnostic Assessment}

The Structured Clinical Interview for DSM-IV (SCID) (First et al. 1996) was used to assess the presence of PTSD and $\mathrm{MD}$, as well as past MD. Inter-rater reliability was good in the present study, with $\kappa=.75$ for PTSD and $\kappa=.86$ for depression ( $n=13$ interviews, 2 raters, blind to each others' diagnoses).

\section{Measures}

General Information Questionnaire. This questionnaire was adapted from earlier studies (Ehring et al. 2008; Halligan et al. 2003) to assess socio-demographic characteristics (age, gender, ethnic background, marital status, income, and education), and drug and alcohol consumption. For each question, participants marked the most appropriate from a selection of answers or filled in answers to open questions.

Trauma History Interview. This semi-structured interview was adapted from Kubany et al. (2000) to assess exposure to a broad range of potentially traumatic events. Sixteen event types (e.g., natural disaster, motor vehicle accidents, sudden, unexpected death of a close friend or loved one, childhood physical or sexual abuse, etc.) are contained in this interview. Participants were asked how old they were when the events happened and how distressing they thought the events were on a rating scale from 0 (not at all stressful) to 100 (extremely stressful). A final open-ended question assesses exposure to some other lifethreatening or highly disturbing event(s). The number of past traumatic events and sum of distress scores were used for the analyses.

Depressive Attributions Questionnaire (DAQ). The DAQ (Kleim et al. 2011) assesses depressive attributions. Items were derived from Beck's cognitive model of depression (e.g., Beck 1967) and the reformulated model of learned helplessness and depression (Abramson et al. 1978). A total of 16 items assessed negative stable attributions (e.g., "When bad things happen, I am sure it will happen again"), negative internal attributions (e.g., "When bad things happen, I think it is my fault"), negative global attributions (e.g., "Bad things happen in all areas of my life"), and helplessness (e.g., "When bad things happen, I rely on other people to sort things out") on a 5-point scale ('not at all', 'a little', 'somewhat', 'strongly', 'very strongly'). Items are combined to a sum score. Internal consistency was excellent in the present study, $\alpha=.96$ for the combined sample.

Post-Traumatic Cognitions Inventory (PTCI). The PTCI (Foa et al. 1999) is a self-report instrument that measures

Table 1 Descriptive information for diagnostic groups: symptom severity and trauma history

\begin{tabular}{|c|c|c|c|c|c|}
\hline Variable & $\begin{array}{l}\text { No diagnosis } \\
(\mathrm{n}=101) \\
\mathrm{n}(\%) / M(S D)\end{array}$ & $\begin{array}{l}\text { PTSD } \\
(\mathrm{n}=17) \\
\mathrm{n}(\%) / M(S D)\end{array}$ & $\begin{array}{l}\mathrm{MD} \\
(\mathrm{n}=20) \\
\mathrm{n}(\%) / M(S D)\end{array}$ & $\begin{array}{l}\mathrm{PTSD}+\mathrm{MD} \\
(\mathrm{n}=26) \\
\mathrm{n}(\%) / M(S D)\end{array}$ & $\begin{array}{l}\text { Total sample } \\
(\mathrm{n}=164) \\
\mathrm{n}(\%) / M(S D)\end{array}$ \\
\hline Depression severity (BDI) & $7.07(6.65)$ & $18.18(8.85)$ & $22.85(9.95)$ & $30.00(10.04)$ & $13.82(12.01)$ \\
\hline PTSD severity (PDS) & $9.93(8.23)$ & $26.00(11.24)$ & $20.70(12.92)$ & $35.36(9.91)$ & $16.84(13.51)$ \\
\hline Number of traumatic events & $4.51(2.88)$ & $6.06(3.01)$ & $6.05(2.96)$ & $6.35(3.35)$ & $5.15(3.06)$ \\
\hline Sum of traumatic distress & $311.76(220.19)$ & $463.65(300.87)$ & $450.90(243.91)$ & $469.77(276.18)$ & $370.70(250.74)$ \\
\hline \multicolumn{6}{|l|}{ Current drug use (past month) } \\
\hline Yes & $19(18.8 \%)$ & $8(47.1 \%)$ & $4(20 \%)$ & $5(19.2 \%)$ & $36(22 \%)$ \\
\hline \multicolumn{6}{|l|}{ Currently medicated } \\
\hline Yes & $21(20.8 \%)$ & $5(29.4 \%)$ & $13(65 \%)$ & $17(65.4 \%)$ & $56(34.1 \%)$ \\
\hline Missing & $1(1 \%)$ & $1(5.9 \%)$ & & & $2(1.2 \%)$ \\
\hline Alcohol units (past week) & $9.05(10.5)$ & $8.86(13.06)$ & $9.78(23.11)$ & $5.68(12.52)$ & 8.57 (12.98) \\
\hline
\end{tabular}


trauma-related thoughts about the self, other people and self-blame (e.g., "My reactions since the event mean that I am going crazy", "The world is a dangerous place"). The 32-item version used in this study asked participants to rate each item on a scale from 1 (totally disagree) to 7 (totally agree). The final score was the sum of all items. The internal consistency in the present study was very good, $\alpha=.95$ for the combined sample.

Response Styles Questionnaire (RSQ). The 10-item rumination scale of the RSQ (Nolen-Hoeksema 1991; Nolen-Hoeksema and Morrow 1991) was used to assess the frequency with which individuals thought about their symptoms of depression, i.e. when they feel sad or depressed, on a four point scale from 1 (never) to 4 (always). Previous studies have shown the RSQ rumination scale to be internally consistent and factor-analytically derivable. Higher scores are related to more severe and longer episodes of depression (e.g., Nolen-Hoeksema et al. 1993) as well as to distorted interpretations of hypothetical life events (Lyubomirsky et al. 1998). The internal consistency in the present study was very good, $\alpha=.93$ for the combined sample.

Post-Traumatic Stress Diagnostic Scale (PDS). The PDS (Foa et al. 1997) is a standardised and validated selfreport measure of PTSD symptom severity that has been widely used with clinical and non-clinical samples of traumatised individuals. The PDS asks participants to rate 17 items regarding how often they were bothered by each of the PTSD symptoms specified in the DSM-IV (APA 1994), ranging from 0 (never) to 3 (5 times per week or more/very severely) and how much these symptoms had interfered with 9 specific areas of their life. The total symptom severity can range from 0 to $51(\leq 10=$ mild; $\geq 11$ and $\leq 20=$ moderate; $\geq 21$ and $\leq 35=$ moderate to severe; $\geq 36=$ severe). Internal consistency in the present study was very good, $\alpha=.95$ for the combined sample.

Beck Depression Inventory (BDI). The BDI (Beck and Steer 1987) is a widely used, standardised and normed measure of severity of depression. The BDI asks participants to decide between four different response choices reflecting different degrees of depressive symptom severity. Items are scored from 0 to 3 . The total BDI score thus ranges between 0 and $63(0-9=$ subclinical; $10-18=$ mild to moderate; $19-29=$ moderate to severe; $30-63=$ severe). Internal consistency in the present study was very good, $\alpha=.91$ for the combined sample.

National Adult Reading Test (NART). The NART (Nelson 1991) is a short measure of verbal intelligence, which consists of a reading test of 50 irregularly spelled words. According to standard instructions, participants read aloud a list of words printed in order of increasing difficulty. The number of words read correctly comprises the final score. A conversion table (from NART to IQ scores) was used to obtain a predicted full-scale IQ. The NART has excellent reliability and construct validity (Crawford et al. 1990).

\section{Study Design and Procedure}

The study was approved by the local ethics committees. Participants gave written consent, filled in questionnaires, and completed diagnostic interviews. They received a modest financial reimbursement for their time.

\section{Statistical Analysis}

We performed one-way ANOVAs and Tukey's honest significance posthoc tests to compare the level of DAQ and PTCI scores and the number of past traumatic events between four diagnostic groups (MD, PTSD, PTSD and MD, and healthy controls). We also calculated Pearson's correlations between DAQ scores and severity of depression symptoms, severity of PTSD symptoms, level of rumination, number of traumatic events, total distress experienced during those events, level of post-traumatic cognitions (PTCI), and NART-predicted full-scale IQ. Finally, we performed standard multiple regressions to assess the ability of the DAQ and the PTCI to predict the severity of depression and PTSD symptoms. All significance tests were two-tailed and the significance level was set at $\alpha=.05$.

\section{Results}

Comparisons Between Diagnostic Groups: Depressive Attributions

Significant differences in DAQ scores were observed between diagnostic groups, $F(3,160)=28.01, P<0.001$. Tukey's posthoc comparisons showed participants with MD only $\left(M_{\text {MD-only }}=33.90 ; S D_{\text {MD-only }}=16.06\right)$ and those with $\mathrm{MD}$ and PTSD $\left(M_{\mathrm{PTSD}+\mathrm{MD}}=37.58 ; S D_{\mathrm{PTSD}+\mathrm{MD}}=16.11\right)$, but not those with PTSD only $\left(M_{\text {PTSD-only }}=22.12\right.$; $\left.S D_{\text {PTSD-only }}=12.24\right)$, scored higher on depressive attributions than healthy controls $\left(M_{\mathrm{H}}=15.54 ; S D_{\mathrm{H}}=10.79\right)$. Additionally, the PTSD only group scored significantly lower on depressive attributions that those with MD only and those with MD and PTSD. Figure 1 illustrates these findings.

Comparisons Between Diagnostic Groups: TraumaRelated Appraisals

Significant differences in the endorsement of trauma-specific appraisals were observed between diagnostic groups, $F(3, \quad 157)=21.37, \quad P<0.001$. Posthoc comparisons 


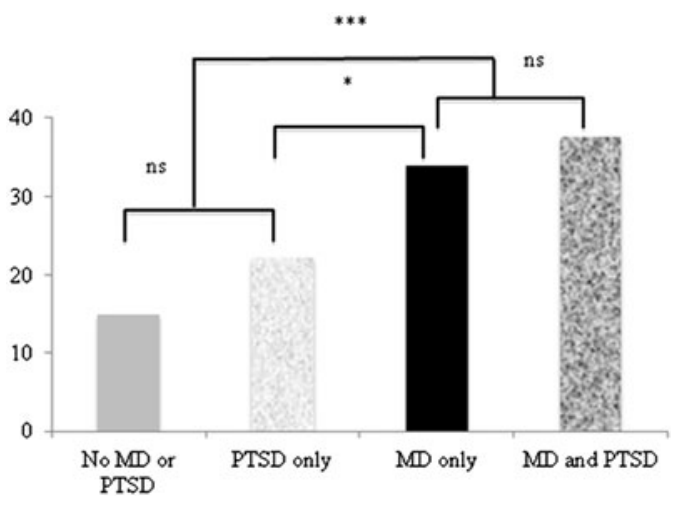

Fig. 1 Comparison of DAQ total scores for diagnostic groups. *** Comparison significant at the $P<0.001$ level; * Comparison significant at the $P<0.050$ level, $\mathrm{ns}=$ not significant

showed that participants with PTSD only $\left(M_{\mathrm{PTSD} \text {-only }}=\right.$ $\left.3.61 ; S D_{\text {PTSD-only }}=.86\right), \quad \mathrm{MD}$ only $\left(M_{\mathrm{MD}-\text { only }}=3.26\right.$; $\left.S D_{\text {MD-only }}=1.16\right)$, and $\mathrm{MD}$ and PTSD $\left(M_{\mathrm{PTSD}+\mathrm{MD}}=\right.$ $4.19 ; S D_{\mathrm{PTSD}+\mathrm{MD}}=1.30$ ) endorsed negative trauma-related appraisals to a greater extent than healthy controls $\left(M_{\mathrm{H}}=2.44 ; S D_{\mathrm{H}}=1.01\right)$. Additionally, those with $\mathrm{MD}$ only endorsed significantly fewer negative appraisals than those with MD and PTSD.

Correlations Between DAQ and Measures of Symptom Severity, Rumination, Number and Distress of Traumatic Events, and Full-Scale IQ

DAQ total scale scores correlated significantly with measures of severity of depression and PTSD symptoms. The correlation between DAQ total scores and the measure of depression severity $(r=.69 ; P<0.001)$ was higher than the correlation between DAQ total scores and the measure of PTSD severity $(r=.55 ; P<0.001)$. However, this difference did not reach significance $(z=1.57 ; P=0.120)$.

DAQ total scores showed significant positive correlations with PTCI total scores $(r=.52, P<0.001)$, with a tendency to ruminate $(r=.65, P<0.001)$, a greater number of traumatic events $(r=.19 ; P<0.050)$, and greater distress experienced during these events $(r=.19$; $P<0.050)$. There was no correlation between DAQ scores and NART-predicted full-scale IQ $(r=-.07 ; P>0.050)$.

Prediction of Depression and PTSD Symptoms Severity by Depressive Attributions and Negative Trauma-

Related Appraisals

Standard multiple regression was used to assess the ability of the DAQ and the PTCI to predict the severity of depression symptoms (BDI). The total variance of depression symptom severity explained by the two independent variables combined (DAQ and PTCI) was $62 \%, R^{2}=.62, F(2,158)=127.3 ; P<0.001 . \mathrm{PTCI}$ alone accounted for $14 \%$ of the variance and DAQ alone for $16 \%$ of the variance. The remaining $32 \%$ corresponds to shared variance. Both the DAQ $(\beta=.47, P<0.001)$ and the PTCI $(\beta=.44, P=<0.001)$, made unique significant contributions.

In the prediction of PTSD, the total variance of PTSD symptom severity (PDS) explained by the DAQ and PTCI total scores was $41 \%, R^{2}=.41 F(2,157)=54.78$; $P<0.001$. PTCI alone accounted for $11 \%$ of the variance and DAQ for $9 \%$ of the variance. The remaining $21 \%$ corresponds to shared variance. Both the PTCI $(\beta=.39$, $P<0.001)$ and the DAQ $(\beta=.35, P \leq 0.001)$ made unique significant contributions.

\section{Discussion}

In accordance with previous findings on the role of attributional style in depression (Abramson et al. 1978; Försterling and Bühner 2003), individuals with major depression endorsed more internal, stable, and global attributions of negative events than participants without depression. This finding provides further support for cognitive theories of depression (Abramson et al. 1978; Abramson et al. 1989; Beck 1967).

The present results extend these previous findings, as this study compared participants with MD only (and no PTSD) with those who only had PTSD (and no depression). We found a significantly higher degree of depressive attributions in those with MD only than in those with PTSD only, who did not differ from healthy controls. Thus, the study provided evidence for some specificity of depressive attributions to depression. Individuals with major depression and comorbid PTSD endorsed depressive attributions to a greater extent than those with PTSD only, but did not differ significantly from those with major depression only. This pattern of results suggests that major depression may be the crucial factor in the endorsement of depressive attributions.

However, in the correlational analyses, depressive attributions correlated with both the severity of depression and PTSD symptoms. This probably reflects the overlap of symptoms of both disorders (e.g., diminished interest in activities, sleep disturbance, difficulty concentrating) and the high comorbidity rates. It may also indicate that depressive attributions are a common transdiagnostic process. Finally, it may also reflect the fact that symptom severity was assessed by self-report and thus shares method variance with the DAQ scores, whereas diagnoses are based on clinicians' judgements. 
DAQ scores correlated with PTCI scores, indicating that causal attributions of negative events in general and negative interpretations about the implications of traumatic events for the self and the world may overlap to some extent (e.g., see DAQ item: "When something I do goes wrong, I think it is because I am incapable"; PTCI item: "I am inadequate"). The multiple regression analyses further showed that depressive attributions and trauma-related negative beliefs were independent predictors of both depressive and PTSD symptoms. This indicates that although they show some overlap, there are also important differences. Whereas the DAQ focuses on the process of assigning a cause to rather generic events (e.g., "When things go well, I think it is just due to good luck"), the PTCI addresses a wider range of cognitions about the meaning of the trauma (e.g., "My life has been destroyed by the event," "I have to be on guard all the time"), and thus possibly explains a wider range of post-trauma symptoms, including those not found in depression, such as hypervigilance.

Individuals who reported more pronounced depressive attributions also reported a higher degree of rumination. Due to the cross-sectional nature of our data, we cannot make inferences about the temporal and potentially causal patterns of these processes. However, one possibility could be that rumination may maintain depressive symptoms as it involves repetitively and passively focusing on the possible causes of symptoms, which may include and enhance depressive cognitions (e.g., Nolen-Hoeksema et al. 2008). Existing research in this area has shown that rumination indeed interacts with depressive symptoms to predict negative attributional style (Lo et al. 2010) and that the interaction between negative cognitive style and stressreactive rumination predicts the onset, number, and duration of prospective depressive episodes (Robinson and Alloy 2003).

Depressive attributions were also associated with greater and more severe exposure to trauma. Again, the crosssectional nature of the data precludes causal interpretations. One could hypothesise a dose-response relationship in that re-exposure to trauma is more likely to result in more pronounced depressive attributions and learned helplessness than one single event. There is evidence that multiple trauma is associated with higher levels of PTSD symptoms (Follette et al. 1996; Green et al. 2000), as well as substance abuse, suicide attempts (McCauley et al. 1997), and mood disorder (Miranda et al. 1997) than single trauma.

It is also relevant to highlight how the DAQ compares with other measures of attributional style, which have been most widely used until now, such as the Attributional Style Questionnaire (ASQ; Peterson et al. 1982) and its expanded and modified version, the Cognitive Style Questionnaire
(CSQ; Haeffel et al. 2008). Both these questionnaires require participants to generate one major cause to positive and negative hypothetical situations from the achievement and affiliation domains (e.g., "You have been looking for a job unsuccessfully for some time", or "You meet a friend who acts hostilely towards you"). In contrast, the DAQ offers short statements containing negative attributions (e.g., "When something I do goes wrong, I think it is because I am incapable") and requires participants to answer on a 0-4 scale how much each statement applies to them. Thus, the DAQ aims to take up less mental processing time and effort, which is crucial during clinical assessment. For instance, depressed individuals often have cognitive deficits in concentration, executive function and over-general memory (Williams et al. 2000) and individuals with PTSD often also present with over-general memory (Schönfeld and Ehlers 2006). In terms of length, the ASQ contains 12 hypothetical events with a total of 60 questions and the CSQ contains 24 hypothetical events, making both these measures much lengthier and more mentally demanding than the DAQ, which contains only 16 brief statements. During the validation process of the DAQ, the ASQ was also administered and several aspects of both questionnaires compared. Mean completion times for the DAQ $(M=2.36 \mathrm{~min}$, $S D=1.15)$ and the ASQ $(M=17.32 \mathrm{~min}, S D=7.73)$ were found to be significantly different for both depressed and non-depressed participants (Kleim et al. 2011). This validation study also showed that both depressed and nondepressed participants found the DAQ significantly easier to fill in than the ASQ. The same study showed that the mean number of ASQ situations for which participants were able to retrieve personal memories was $7.36, S D=2.30(61 \%)$ and they also specified some difficulties completing the ASQ but not the DAQ. In addition, both the ASQ and the CSQ were validated in samples of college students, whereas the DAQ was validated in participants from various diagnostic groups and healthy controls, making the latter a more appropriate tool for clinical use. Finally, the ASQ's low reliability has been criticised in some studies (e.g., Sweeney et al. 1986) and there are sparse data on its validity. In contrast the DAQ has been shown to have high internal reliability, test-retest reliability, and convergent, discriminant and construct validity. Thus, although the differences between the DAQ and other measures might make it difficult to compare results across studies, it is important to introduce a measure of attributional style, which addresses the shortcomings of previous ones, i.e. (1) ease of use, (2) applicability to different participant groups, and (3) validity and reliability in clinical and research settings.

This study is not without limitations. First, we used the DAQ to index core aspects of depressive attributions, namely internal, stable and global attributions of negative events. It might also be useful to investigate other 
attributional dimensions reported in the literature, such as controllability, expectedness, and importance of events. Second, our study is cross-sectional. It would be clinically relevant to test the predictive power of depressive attributions in the development of depression and PTSD symptoms in prospective studies. If these yielded positive results, a measure of depressive attributions could be used as a screening tool to detect individuals at high risk of developing MD or PTSD. Finally, our results would be strengthened by replication in further samples. Our analysis into the specificity of depressive attributions is limited to the comparison between MD and PTSD. It would be interesting to include further groups into the comparison, such as individuals with substance abuse or bipolar disorder.

The present results have implications for theory, as well as practical clinical implications. Some effective empirically-based therapies, for instance cognitive-behavioural therapies, address patients' maladaptive beliefs, and attempt to modify them by developing alternative explanations for events and gathering evidence for various explanations to create more evidence-based adaptive beliefs (Beck 1976; Ehlers et al. 2005; Ingram 2007; Kuyken et al. 2007; Markowitz 2008). According to current cognitive behavioural models, thoughts, including depressive attributions and negative trauma-related beliefs, influence behaviour, and may lead to the development and maintenance of clinical disorders, such as MD or PTSD. Attributional retraining has been described as an empirically based cognitive-behavioural technique, for instance in the treatment of child victims of sexual abuse, which involved decreasing abuse-related self-blame and encouraging the child to attribute responsibility for the abuse to the perpetrator (Celano et al. 2002). Dieser and Ruddell (2002) examined the effects of attributional retraining on attributions and explanatory style in depressed adolescent inpatients and reported that the training led to higher endorsement of personal control and stability attributions. Moreover, a recent experimental study by Peters, Constans, and Mathews (2011) showed that attributional style can be manipulated by use of computer-based cognitive bias modification (CBM). This training resulted in a decreased tendency to engage in negative causal attributions for poor performance and in less depressed mood. Identifying and modifying disorder-specific attributions and appraisals and their identification may thus be an important target of disorderspecific psychological therapies (e.g. Miller et al. 1975).

Acknowledgments We gratefully acknowledge the support of the Wellcome Trust (grant 069777) and the Psychology Research Trust. We would like to thank Daniel Stahl for his support and advice regarding statistical analyses of data. Special thanks to all participants, who patiently contributed to the collection of data for this investigation.
Open Access This article is distributed under the terms of the Creative Commons Attribution Noncommercial License which permits any noncommercial use, distribution, and reproduction in any medium, provided the original author(s) and source are credited.

\section{References}

Abramson, L. Y., Alloy, L. B., Hogan, M. E., Whitehouse, W. G., Cornette, M., Akhaven, S., et al. (1998). Suicidality and cognitive vulnerability to depression among college students: a prospective study. Journal of Adolescence, 21, 473-487. doi: 10.1006/jado.1998.0167.

Abramson, L. Y., Metalsky, G. I., \& Alloy, L. B. (1988). The hopelessness theory of depression: Does the research test the theory? In L. Y. Abramson (Ed.), Social cognition and clinical psychology: A synthesis. New York: Guilford.

Abramson, L. Y., Metalsky, G. I., \& Alloy, L. B. (1989). Hopelessness depression: A theory-based subtype of depression. Psychological Review, 96, 358-372. doi:10.1037/0033-295X.96.2.358.

Abramson, L. Y., Seligman, M. E. P., \& Teasdale, J. (1978). Learned helplessness in humans: Critique and reformulation. Journal of Abnormal Psychology, 87, 49-74. doi:10.1037/0021-843X. 87.1.49.

Alloy, L. B., Abramson, L. Y., Metalsky, G. I., \& Hartlage, S. (1988). The hopelessness theory of depression: Attributional aspects. British Journal of Clinical Psychology, 27, 5-21. doi:10.1111/ j.2044-8260.1988.tb00749.x.

Alloy, L. B., Abramson, L. Y., Whitehouse, W. G., Hogan, M. E., Panzarella, C., \& Rose, D. T. (2006). Prospective incidence of first onsets and recurrences of depression in individuals at high and low cognitive risk for depression. Journal of Abnormal Psychology, 115, 145-156. doi:10.1037/0021-843X.115.1.145.

Alloy, L. B., Abramson, L. Y., Whitehouse, W. G., Hogan, M. E., Tashman, N. A., Steinberg, D. L., et al. (1999). Depressogenic cognitive styles: Predictive validity, information processing and personality characteristics, and developmental origins. Behavioural Research and Therapy, 37(6), 503-531. doi:10.1016/ S0005-7967(98)00157-0.

Association, American. Psychiatric. (1994). Diagnostic and statistical manual of mental disorders (4th ed.). Washington, D.C.: American Psychiatric Association.

Ball, H. A., McGuffin, P., \& Farmer, A. E. (2008). Attributional style and depression. The British Journal of Psychiatry, 192, 275-278. doi:10.1192/bjp.bp.107.038711.

Beck, A. T. (1967). Depression: Clinical, experimental and theoretical aspects. New York: Harper \& Row.

Beck, A. T. (1976). Cognitive therapy and the emotional disorders. New York: International Universities Press.

Beck, A. T., \& Steer, R. A. (1987). Beck depression inventory: Manual. San Antonio, TX: Psychological Coorporation.

Breslau, N., Davis, G. C., Andreski, P., \& Peterson, E. (1991). Traumatic events and posttraumatic stress disorder in an urban population of young adults. Archives of General Psychiatry, $48(3), 216-222$.

Celano, M., Hazzard, A., Campbell, S. K., \& Lang, C. B. (2002). Attribution retraining with sexually abused children: Review of techniques. Child Maltreatment, 7(1), 65-76. doi:10.1177/10775 59502007001006.

Crawford, J. R., Cochrane, R. H. B., Besson, J. A., Parker, D. M., \& Stewart, L. E. (1990). Premorbid IQ estimates obtained by combining the NART and demographic variables: Construct validity. Personality and Individual Differences, 11(2), 209-210. doi:10.1016/0191-8869(90)90018-M. 
Dieser, R. B., \& Ruddell, E. (2002). Effects of attribution retraining during therapeutic recreation on attributions and explanatory styles of adolescents with depression. Therapeutic Recreation Journal, 36(1), 35-47.

Dollinger, S. J. (1986). The need for meaning following disaster: Attributions and emotional upset. Personality and Social Psychology Bulletin, 12, 300-310. doi:10.1177/0146167286123006.

Ehlers, A., \& Clark, D. M. (2000). A cognitive model of posttraumatic stress disorder. Behaviour Research and Therapy, 38(4), 319-345. doi:10.1016/S0005-7967(99)00123-0.

Ehlers, A., Clark, D. M., Hackmann, A., McManus, F., \& Fennell, M. (2005). Cognitive therapy for post-traumatic stress disorder: Development and evaluation. Behaviour Research and Therapy, 43(4), 413-431. doi:10.1016/j.brat.2004.03.006.

Ehring, T., Ehlers, A., \& Glucksman, E. (2008). Do cognitive models help in predicting the severity of posttraumatic stress disorder, phobia, and depression after motor vehicle accidents? A prospective longitudinal study. Journal of Consulting and Clinical Psychology, 76(2), 219-230. doi:10.1037/0022-006X.76.2.219.

Elwood, L. S., Hahn, K. S., Olatunji, B. O., \& Williams, N. L. (2009a). Cognitive vulnerabilities to the development of PTSD: A review of four vulnerabilities and the proposal of an integrative vulnerability model. Clinical Psychology Review, 29, 87-100. doi:10.1016/j.cpr.2008.10.002.

Elwood, L. S., Mott, J., Williams, N. L., Lohr, J. M., \& Schroeder, D. A. (2009b). Attributional style and anxiety sensitivity as maintenance factors of posttraumatic stress symptoms: A prospective examination of a diathesis-stress model. Journal of Behavior Therapy and Experimental Psychiatry, 40, 544-557. doi:10.1016/j.jbtep.2009.07.005.

First, M. B., Spitzer, R. L., Gibbon, M., \& Williams, J. B. W. (1996). Structured clinical interview for DSM-IV axis I disorders. Washington, D.C.: American Psychiatric Press.

Foa, E. B., Cashman, L., Jaycox, L., \& Perry, K. (1997). The validation of a selfreport measure of posttraumatic stress disorder: The posttraumatic diagnostic scale. Psychological Assessment, 9, 445-451. doi:10.1037/1040-3590.9.4.445.

Foa, E. B., Ehlers, A., Clark, D. M., Tolin, D. F., \& Orsillo, S. M. (1999). The posttraumatic cognitions inventory (PTCI): Development and validation. Psychological Assessment, 11, 303-314. doi:10.1037/1040-3590.11.3.303.

Foa, E. B., \& Riggs, D. S. (1993). Posttraumatic stress disorder and rape. In J. M. Oldham, M. B. Riba, \& A. Tasman (Eds.), American psychiatric press review of psychiatry (pp. 273-303). Washington, DC: American Psychiatric Press.

Follette, V. M., Polusny, M., Bechtle, A. E., \& Naugle, A. E. (1996). Cumulative trauma: The impact of child sexual abuse, adult sexual abuse, and spouse abuse. Journal of Traumatic Stress, 9, 25-35. doi:10.1002/jts.2490090104.

Försterling, F., \& Bühner, M. (2003). Attributional veridicality and evaluative beliefs: How do they contribute to depression? Journal of Social and Clinical Psychology, 22(4), 369-392. doi: $10.1521 /$ jscp.22.4.369.22894

Frye, J., \& Stockton, R. A. (1982). Discriminant analysis of posttraumatic stress disorder among a group of Vietnam veterans. American Journal of Psychiatry, 139, 52-56.

Gibb, B. E., Alloy, L. B., Abramson, L. Y., Rose, D. T., Whitehouse, W. G., \& Hogan, M. E. (2001). Childhood maltreatment and college students' current suicidal ideation: A test of the hopelessness theory. Suicide Life Threatening Behavior, 31(4), 405-415. doi:10.1521/suli.31.4.405.22042.

Ginzburg, K., Solomon, Z., Dekel, R., \& Neria, Y. (2003). Battlefield functioning and chronic PTSD: Associations with perceived self efficacy and causal attribution. Personality and Individual Differences, 34, 463-476. doi:10.1016/S0191-8869(02)00066-1.
Gray, M. J., Pumphrey, J. E., \& Lombardo, T. W. (2003). The relationship between dispositional pessimistic attributional style versus trauma-specific attributions and PTSD symptoms. Anxiety Disorders, 17, 289-303. doi:10.1016/S0887-6185(02)00205-0.

Green, B. L., Goodman, L. A., Krupnick, J. L., Corcoran, C. B., Petty, R. M., Stockton, P., et al. (2000). Outcomes of single versus multiple trauma exposure in a screening sample. Journal of Traumatic Stress, 13(2), 271-286. doi:10.1023/A:100775871 1939.

Haeffel, G. J., Gibb, B. E., Metalsky, G. I., Alloy, L. B., Abramson, L. Y., Hankin, B. L., et al. (2008). Measuring cognitive vulnerability to depression: Development and validation of the cognitive style questionnaire. Clinical Psychology Review, 28, 824-836. doi:10.1016/j.cpr.2007.12.001.

Halligan, S. L., Michael, T., Clark, D. M., \& Ehlers, A. (2003). Posttraumatic stress disorder following assault: The role of cognitive processing, trauma memory, and appraisals. Journal of Consulting and Clinical Psychology, 71, 419-431. doi: 10.1037/0022-006X.71.3.419.

Hankin, B. L., Abramson, L. Y., Miller, N., \& Haeffel, G. J. (2004). Cognitive vulnerability-stress theories of depression: examining affective specificity in the prediction of depression versus anxiety in three prospective studies. Cognitive Therapy and Research, 28(3), 309-345. doi:10.1023/B:COTR.0000031805. 60529.0d.

Hilsman, R., \& Garber, J. (1995). A test of the cognitive diathesisstress model of depression in children: Academic stressors, attributional style, perceived competence, and control. Journal of Personality and Social Psychology, 69(2), 370-380. doi: 10.1037/0022-3514.69.2.370.

Ingram, R. E. (2007). Introduction to the special section on cognitive processes and psychotherapy. Journal of Consulting and Clinical Psychology, 75(3), 359-362. doi:10.1037/0022-006X.75.3.359.

Joseph, S. A., Brewin, C. R., Yule, W., \& Williams, R. (1991). Causal attributions and psychiatric symptoms in survivors of the Herald of free enterprise disaster. British Journal of Psychiatry, 159, 542-546. doi:10.1192/bjp.159.4.542.

Kessler, R. C., Sonnega, A., Bromet, E., Hughes, M., \& Nelson, C. B. (1995). Posttraumatic stress disorder in the national comorbidity survey. Archives of General Psychiatry, 52, 1048-1060.

Kleim, B., Ehlers, A., \& Glucksman, E. (in press). Investigating cognitive pathways to psychopathology: Predicting depression and posttraumatic stress disorder from early responses after assault. Psychological Trauma: Theory, Research, Practice, and Policy.

Kleim, B., Gonzalo, D., \& Ehlers, A. (2011). The depressive attributions questionnaire (DAQ): Development of a short selfreport measure of depressogenic attributions. Journal of Psychopathology and Behavioral Assessment, 33(3), 375-385. doi: 10.1007/s10862-011-9234-9.

Kubany, E. S., Haynes, S. N., Leisen, M. B., Owens, J. A., Kaplan, A. S., Watson, S. B., et al. (2000). Development and preliminary validation of a brief broad-spectrum measure of trauma exposure: The traumatic life events questionnaire. Psychological Assessment, 12, 210-224. doi:10.1037/1040-3590.12.2.210.

Kuyken, W., Dalgleish, T., \& Holden, E. R. (2007). Advances in cognitive-behavioural therapy for unipolar depression. Canadian Journal of Psychiatry, 52, 5-13.

Laposa, J. M., \& Alden, L. E. (2003). Posttraumatic stress disorder in the emergency room: Exploration of a cognitive model. Behaviour Research and Therapy, 41, 49-65. doi:10.1016/S0005-7967(01) 00123-1.

Lo, C. S. L., Ho, S. M. Y., \& Hollen, S. D. (2010). The effects of rumination and depressive symptoms on the prediction of negative attributional style among college students. Cognitive 
Therapy and Research, 34(2), 116-123. doi: 10.1007/s10608-009-9233-2.

Lyubomirsky, S., Caldwell, N. D., \& Nolen-Hoeksema, S. (1998). Effects of ruminative and distracting responses to depressed mood on retrieval of autobiographical memories. Journal of Personality and Social Psychology, 75, 166-177. doi: 10.1037/0022-3514.75.1.166.

Markowitz, J. C. (2008). Evidence-based psychotherapies for depression. Journal of Occupational and Environmental Medicine, 50, 437-440. doi:10.1097/JOM.0b013e318168f76e.

Mayou, R. A., Bryant, B., \& Ehlers, A. (2001). Predictors of psychiatric morbidity 1 year after motor vehicle accidents. American Journal of Psychiatry, 158, 1231-1238. doi:10. 1176/appi.ajp.158.8.1231

McCauley, J., Kern, D. E., Kolodner, K., Dill, L., Schroeder, A. F., DeChant, H. K., et al. (1997). Clinical characteristics of women with a history of childhood abuse: Unhealed wounds. Journal of the American Medical Association, 277, 1362-1368. doi: 10.1001/jama.277.17.1362.

McCormick, R. A., Taber, J., \& Kruedelbach, N. (1989). The relationship between attributional style and post-traumatic stress disorder in addicted patients. Journal of Traumatic Stress, 2, 477-487. doi:10.1002/jts.2490020410.

Miller, R. L., Brickman, P., \& Bolen, D. (1975). Attribution versus persuasion as a means of modifying behaviour. Journal of Personality and Social Psychology, 31, 430-441. doi:10. 1037/h0076539.

Miranda, J. M., Green, B. L., \& Krupnick, J. (1997, December). Mental disorders in disadvantaged gynecology patients. Paper presented at the North American meeting of the society for psychotherapy research, Tucson, AZ.

Nelson, H. (1991). National adult reading test (NART). Test manual. Windsor: NFER-Nelson.

Nolen-Hoeksema, S. (1991). Responses to depression and their effects on the duration of depressive episodes. Journal of Abnormal Psychology, 100, 569-582. doi:10.1037/0021-843X.100.4.569.

Nolen-Hoeksema, S., \& Morrow, J. (1991). A prospective study of depression and posttraumatic stress symptoms after a natural disaster: The 1989 Loma Prieta earthquake. Journal of Personality and Social Psychology, 61, 115-121. doi:10.1037/ 0022-3514.61.1.115.

Nolen-Hoeksema, S., Morrow, J., \& Fredrickson, B. L. (1993). Response styles and the duration of episodes of depressed mood. Journal of Abnormal Psychology, 102, 20-28. doi:10.1037/ 0021-843X.102.1.20.

Nolen-Hoeksema, S., Wisco, B. E., \& Lyubomirsky, S. (2008). Rethinking rumination. Perspectives on Psychological Science, 3(5), 400-424. doi:10.1111/j.1745-6924.2008.00088.x.

O’Donnell, M. L., Creamer, M., \& Pattison, P. (2004). Posttraumatic stress disorder and depression following trauma: Understanding comorbidity. American Journal of Psychiatry, 161, 1390-1396. doi:10.1176/appi.ajp.161.8.1390.

Peters, K. D., Constans, J. I., \& Mathews, A. (2011). Experimental modification of attribution processes. Journal of Abnormal Psychology, 120(1), 168-173. doi:10.1037/a0021899.

Peterson, C., Semmel, A., von Baeyer, C., Abramson, L. Y., Metalsky, G. I., \& Seligman, M. E. P. (1982). The attributional style questionnaire. Cognitive Therapy and Research, 6, 287-300. doi:10.1007/BF01173577.

Resick, P. A., \& Schnicke, M. K. (1993). Cognitive processing therapy for rape victims. Newbury Park, CA: Sage.

Robinson, M. S., \& Alloy, L. B. (2003). Negative cognitive styles and stress-reactive rumination interact to predict depression: A prospective study. Cognitive Therapy and Research, 27(3), 275-291. doi:10.1023/A:1023914416469.

Schönfeld, S., \& Ehlers, A. (2006). Overgeneral memory extends to pictorial retrieval cues and correlates with cognitive features in posttraumatic stress disorder. Emotion, 6(4), 611-621.

Shalev, A. Y., Freedman, S., Peri, T., Brandes, D., Sahar, T., Orr, S. P., et al. (1998). Prospective study of posttraumatic stress disorder and depression following trauma. American Journal of Psychiatry, 155, 630-637.

Southall, D., \& Roberts, J. E. (2002). Attributional style and self-esteem in vulnerability to adolescent depressive symptoms following life stress: A 14-week prospective study. Cognitive Therapy and Research, 26(5), 563-579. doi:10.1023/A:1020457508320.

Sweeney, P. D., Anderson, K., \& Bailey, S. (1986). Attributional style in depression: A meta-analytic review. Journal of Personality and Social Psychology, 50, 974-991. doi:10.1037/0022-3514. 50.5.974.

Taylor, S. (1983). Adjustment to threatening life events: A theory of cognitive adaptation. American Psychologist, 38, 1161-1173. doi:10.1037/0003-066X.38.11.1161.

Voelz, Z. R., Haeffel, G. J., Joiner, T. E., \& Dineen Wagner, K. (2003). Reducing hopelessness: the interaction of enhancing and depressogenic attributional style for positive and negative life events among youth psychiatric inpatients. Behaviour Research and Therapy, 41(10), 1183-1198. doi:10.1016/S0005-7967 (03)00030-5.

Wenninger, K., \& Ehlers, A. (1998). Dysfunctional cognitions and adult psychological functioning in child sexual abuse survivors. Journal of Traumatic Stress, 11, 281-300. doi:10.1023/A:1024451103931.

Williams, J. M. G., Teasdale, J. D., Segal, Z. V., \& Soulsby, J. (2000). Mindfulness-based cognitive therapy reduces overgeneral autobiographical memory in formerly depressed patients. Journal of Abnormal Psychology, 109(1), 150-155.

Zullow, H. M., Oettingen, G., Peterson, C., \& Seligman, M. E. P. (1988). Pessimistic explanatory style in the historical record. American Psychologist, 43(9), 673-682. doi:10.1037/0003066X.43.9.673. 